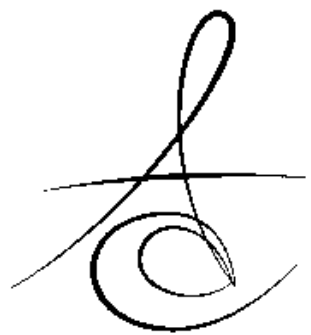

\title{
DENTAL TRAVMAYA UĞRAMIŞ GENÇ DAİMİ KESER DİŞLERE REJENERATİ ENDODONTİK TEDAVİ UYGULAMASI: İKİ OLGU RAPORU
}

\section{REGENERATIVE ENDODONTIC TREATMENT OF IMMATURE PERMANENT INCISORS FOLLOWING DENTAL TRAUMA: A REPORT OF 2 CASES}

\section{ÖZET}

Travmatik yaralanmaya uğramış olan gelişimini tamamlamamış daimi dişlerde kök kanal tedavisi uygulaması diş hekimleri için büyük zorluklar taşımaktadır. Son yıllarda bu tür dişlerin tedavi için geliştirilmiş biyolojik temele dayalı rejeneratif endodontik tedavi yöntemi sunulmuştur. Bu çalışmanın amacı genç (apeksi açık), dental travmaya uğramış ve nekroz olan daimi dişlerde revaskülarizasyon tedavisini uygulanması ve tedavi sonuçlarının rapor edilmesi amacıyla yapılmıştır. Çalışmamızda 6 yaşındaki bir erkek çocuğunun sol üst orta keser dişinin intrüze, sağ üst orta keser dişinin ise sublükse olduğu belirlenmiş olup bu dişlere rejeneratif endodontik tedavi uygulanmıştır. Yirmi-dört aylık takip periyodu sonucunda sağ üst orta keser dişte periapikal iyileşme ve apeksogenesis görülmüş olmasına karşın, sol üst orta keser dişte ise periapikal lezyonlar ve kök rezopsiyonu gözlenmiştir. Rejeneratif endodontik tedavi süblükse, nekrotik ve açık apeksli dişlerde başarılı sonuçlar ortaya koymuş ve bu tür olgularda standart bir prodedür olarak uygulanabileceği kanıtlanmış olmasına karşın, intrüze olan daimi dişleri için ise bu tedavi yönteminin uygun olmadığı belirlenmiştir. Diğer taraftan, bu konu ile ilgili daha fazla ve uzun dönem takipler içeren çalışmalara ihtiyaç duyulmaktadır.

Anahtar kelimeler: Rejeneratif endodontic tedavi, dental travma, genç daimi diş

\section{GİRIş}

Çürük veya travmaya maruz kalmış, kök gelişimini tamamlamamış daimi dişler, diş hekimleri için hep sorun oluşturmuştur. ${ }^{1}$ Nekrotik ve kök gelişimini tamamlamamış dişlerde kök anatomisi

\section{ABSTRACT}

Immature permanent teeth damaged by caries or trauma can present a challenge to dentistry. Recently a biologically based treatment called regenerative endodontic treatment was introduced. The purpose of this report was to present a case of pulp revascularization in immature, traumatized and necrotic teeth. An 6-year-old male presented with intruzed and subluxation to the permanent maxillary left and right central incisors, respectively. Revascularization therapy was performed over multiple visits. At 24 months follow-up, healing of the periapical area and apexogenesis were found to be complete in right incisor. however, left incisor presented periapical lesion and root resorption. Although with an increasing breadth of clinical evidence and practitioner acceptance, regenerative techniques may become a standard technique in treating subluxed immature necrotic permanent teeth, this treatment procedure is not useful for intruzed permanent teeth. On the other hand, further and long-term clinical researches are required.

Keywords: Regenerative endodontic treatment, dental trauma, immature permanent teeth

* Erciyes Üniversitesi, Diş Hekimliği Pedodonti AnabilimDalı

tamamlanmadığından dolayı için geleneksel endodontik tedavi uygulamaları kendisine fazla bir yer bulamamaktadır. 2,3 Yapılan çalışmalar genç daimi dişlerin, nekroz olduktan sonra revaskülarizasyonunun mümkün olduğunu ortaya koymuştur. ${ }^{4,5}$ 
Dişlerde oluşan travmatik yaralanmalar pulpal ve periapikal hasarlara neden olabilir. Çoğu diş travmaları 7 -10 yaş aralığında, kök gelişimi tamamlanmadan oluşmaktadır.6,7 İntrüzyon yaralanması, daimi dişlerde oluşan bütün travmaların \%1,9 unu oluşturmaktadır. ${ }^{3}$ Travmaya uğramış, kök gelişimini tamamlamamış daimi diş canlılığını yitirdiği zaman endodontik tedavi sorun olabilmektedir. Bu dişlerde geleneksel tedavi yöntemleri uygulandığı zaman sızdırmazlık sağlanamayabilir. Ayrıca, ince kök kanal duvarları uzun vadede dişi kök kırığına yatkın hale getirmektedir. $^{8} \mathrm{Bu}$ tür olgularda çoğunlukla iki farklı geleneksel tedavi yönteminden birisi uygulanmaktadır. Bu tedavi yöntemleri; uzun süren kalsiyum hidroksit ile apeksifikasyon ya da apikal bölgede yapay bariyer oluşturarak yapılan tek seans süren apeksifikasyon tedavisidir. Bununla birlikte, son zamanlarda, rejeneratif endodontik tedavi uygulamaları üzerine yapılan çalışmalar dikkat çekmektedir. Bu tedavinin en önemli avantajı apeks kapanma işlemi gerçekleşirken aynı zamanda kök gelişimininde devam etmesidir. ${ }^{9}$

$\mathrm{Bu}$ olgu sunumunda subluksasyon yaralanması olan dişin rejeneratif endodontik tedavi sonucunda kök gelişiminin devam ettiği ve vitalite testine pozitif cevap verdiği görülmüştür. Buna karşın aynı hastanın intruzyon yaralanması olan dişinin kök gelişiminin devam etmediği ve vitalite testine negatif cevap verdiği görülmüştür.

\section{OLGU SUNUMU}

6 yaşındaki erkek hasta Erciyes Üniversitesi Diş Hekimliği Fakültesi Pedodonti Kliniğine travma sonucu başvurmuştur. Alınan dental anamnezde dental travma olayının kliniğe başvurmadan 2 saat önce okulda koşarken düşmesi sonucu oluştuğu belirlenmiştir. Alınan tıbbi anamnezde hastanın sistemik bir hastalığı olmadığı, herhangi bir şeye karşı bilinen bir alerjisi olmadığı bildirilmiştir. Klinik muayene sonucunda 11 numaralı dişte subluksasyon yaralanması olduğu, 21 numaralı dişte ise yaklaşık 4 mmlik intruzyon yaralanması olduğu belirlenmiştir. Ayrıca dudak ve dişetinde kanama oluştuğu gözlemlenmiştir. Radyografik muayenede her iki dişin apekslerinin açık olduğu gözlenmiştir. Ayrıca dişin kronunda ya da kökünde herhangi bir kırık mevcudiyetine rastlanmamıştır (Şekil 1)

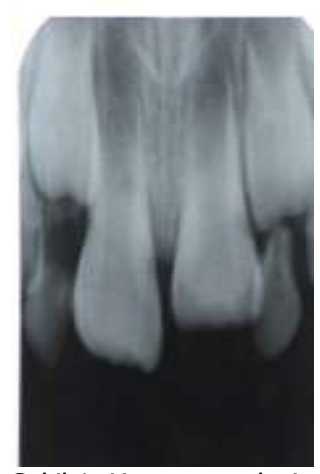

Şekil 1. Hastanın tedavi öncesi radyografik görüntüsü.

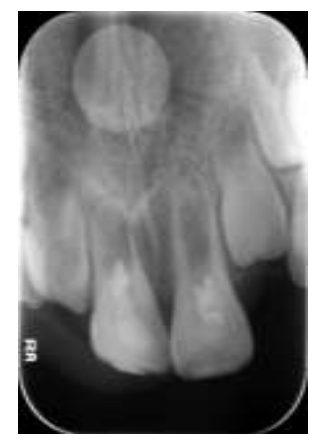

Şekil 2. Hastanın tedaví sonrası 3. aydaki radyografik görüntüsü.

\section{Tedavi Planlaması}

Subluksasyon yaralanması olan 11 nolu dişte 2 hafta ve İntrüze olan 21 nolu dişin spontan erüpsiyonu için 3 hafta bekledikten sonra yapılan vitalite testlerinden negatif cevap alınmasından dolayı iki dişe de rejeneratif endodontik tedavi uygulanmasına karar verilmiştir.

Dişlerin, $2 \%$ Lidokain ve 1:800.000 epinefrin içeren lokal anestezi ( Xylocaine \% 2 , Dentsply , Addlestone, UK) ile anestezisi sağlanmış ve rubber dam ile izole edilmiştir. Bol su altında yüksek hızlı elmas rond frez ile giriş kavitesi açılmış, kanal içi \%6 Iık NaoCl ile irrige edilmiştir. Daha sonra röntgen ile kontrol edilerek \# $20 \mathrm{~K}$ - file (Dentsply) ile apikal bölgeden taşırılarak kanal boşluğu boyunca kanama oluşturulmuştur. Mine-sement birleşim seviyesinde pıhtı oluşumu sağlanmıştır. Mineral trioxide aggregate ( ProRoot MTA, Dentsply, Tulsa, OK, ABD) distile su ile karıştırılıp pıhtı üzerine konulmuştur. MTA nın üzerine nemlendirilmiş steril pamuk pelet konulup güçlendirilmiş çinko oksit ojenol restorasyonla (IRM, Dentsply, Surrey, İngiltere) geçici olarak kapatılmıştır. Daimi kompozit restorasyon (Filtek Z350, 3M ESPE, St Paul, MN, ABD ) 96saat sonra yapılmış olup daha sonrasında olgu üç er aylık randevu aralıkları ile 2 yıl takip edilmiştir.

İlk 3 ay sonunda 11 ve 21 nolu dişler asempomatik ve her ikisi de elektrikli pulpa testine testine negatif cevap vermiştir (Şekil 2). Altıncı ayda 11 nolu dişin kök gelişimi devam ederken 21 nolu dişte değişiklik gözlenmemiştir ve elektrik pulpa testine negatif cevap vermiştir (Şekil 3). Dokuzuncu ayda 11 nolu dişin kök gelişimi devam ederken, elektrik testine pozitif cevap vermiştir, 21 nolu dişte ise lezyon görül-

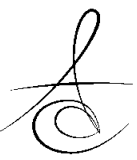


meye başlanmıştır (Şekil 4). Bundan sonraki randevularda $(12,15,18$ ve 21 . Aylar) 11 nolu dişin kök gelişimi devam ederken, 21 nolu dişle lezyonun genişlediği gözlenmiştir (Şekil 5,6,7,8). Yirmi dördüncü aya gelindiğinde 11 nolu dişte apikal kapanma sağlanmış olup elektrikli pulpa testine ise pozitif cevap alınmaya devam edildiği kaydedilmiştir. Buna karşın 21 nolu dişte ise lezyon genişlemiş olup elektrikli pulpa testine de negatif cevap alındığı kaydedilmiştir (Şekil 9).

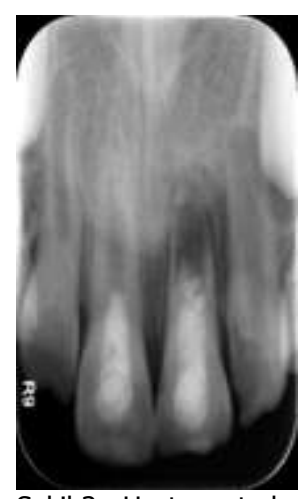

Şekil 3. Hastanın tedavi sonrası 6. aydaki radyografik görüntüsü.

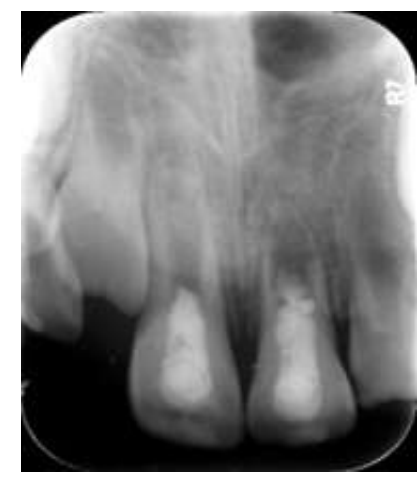

Şekil 4. Hastanın tedavi sonrası 9. aydaki radyografik görüntüsü.

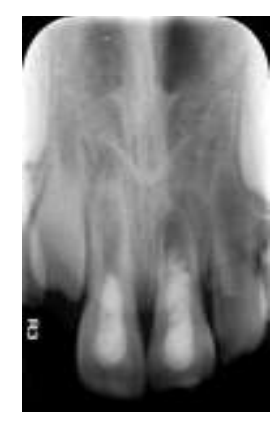

Şekil 5. Hastanın tedavi sonrası 12. Aydaki radyografik görüntüsü.

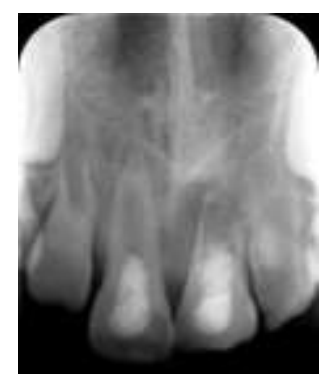

Şekil 7.Hastanın tedavi sonrası 18. Aydak radyografik görüntüsü.

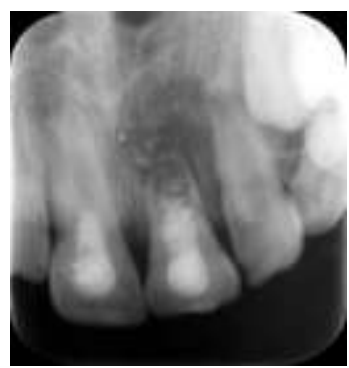

Şekil 9.Hastanın tedavi sonrası 24. aydaki radyografik görüntüsü.

\section{TARTIŞMA}

Bu çalışmada travma sonucu intrüze olan ve subluksasyona uğrayan üst orta keser dişlerin rejeneratif endodontik tedavisi ve sonuçlarının değerlendirilmesi amaçlanmıştır. Kontrol randevularında yapılan klinik muayenelerde 11 numaralı dişte hiçbir semptom yokken 21 nolu dişte perküsyona hafif bir hassasiyet gözlenmiştir. Radyografik muayenede ise 11 nolu dişte kök gelişimi devam etmekte ve elektrikli vitalite testine pozitif cevap vermekte iken (Şekil 2-8) 21 nolu dişte kök gelişimi gözlenmemiş, kökte lezyon oluşmuştur (Şekil 9).

Gelman ve Park ${ }^{10}$ yaptıkları çalışmada nekrotik dişlere uygulanan rejeneratif endodontik tedavi sonucunda üçüncü ayda yapılan klinik muayenede hastada perküsyon hassasiyeti olmadığı, kök gelişiminin devam ettiği ve apikal kapanmanın sağlandığı görülmüştür. Buna karşın bizim çalışmamızda ise 11 nolu dişte aynı bulgular altıncı ayda gözlenmiştir (Şekil 3). Başka bir çalışmada travmaya uğramış dişlerde MTA apeksifikasyonunun, rejeneratif endodontik tedaviye göre daha yararlı olabileceği belirtilmiştir. ${ }^{11}$

Güzeler ve arkadaşları ${ }^{12}$ yaptığı çalışmada da travmaya uğramış dişlerin, özellikle intrüzyon, lüksasyon ve avülsüyon vakalarında kök rezorbsiyonun en önemli komplikasyon olduğu vurgulanmıştır. Aynı şekilde, bizim çalışmamızda da 21 nolu intrüze olan dişte kök rezorbsiyonu gözlenmiştir (Şekil 2-9).

Yapılan takip ve gözlemler rejeneratif endodontik tedavinin geleneksel apeksifikasyon tedavisi için etkin bir alternatif olduğunu göstermiştir. Vitalite testi sonucu 1 yıl sonra bile pozitif cevap verebilmektedir. Fakat intrüzyon yaralanmalarında bu tedavi yaklaşımı istenmeyen sonuçlar gösterebileceği belirtilmiştir. ${ }^{13,14}$ Pek çok pedodonti ve endodonti uzmanı gelecekte rejeneratif tekniklerin uygun bir seçenek olduğunu kabul etmektedirler. ${ }^{14-17}$

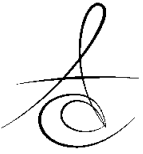




\section{KAYNAKLAR}

1. Trope M. Avulsion of permanent teeth: theory to practice. Dent Traumatol 2011;27:281-94.

2. Andreasen JO, Andreasen FM, Skeie A, HjortingHansen E, Schwartz O. Effect of treatment delay upon pulp and periodontal healing of traumatic dental injuries -- a review article. Dent Traumatol 2002;18:116-28.

3. Andreasen JO, Bakland LK, Andreasen FM. Traumatic intrusion of permanent teeth. Part 3. A clinical study of the effect of treatment variables such as treatment delay, method of repositioning, type of splint, length of splinting and antibiotics on 140 teeth. Dent Traumatol 2006;22:99-111.

4. Wilkinson $\mathrm{DL}$, McCarthy $\mathrm{M}$. Use of comparative data for integrated cancer services. BMC Health Serv Res 2007;7:204.

5. Chueh LH, Ho YC, Kuo TC, Lai WH, Chen YH, Chiang CP. Regenerative endodontic treatment for necrotic immature permanent teeth. J Endod 2009;35:160-4.

6. Andreasen JO, Ravn JJ. Epidemiology of traumatic dental injuries to primary and permanent teeth in a Danish population sample. Int J Oral Surg 1972;1:235-9.

7. Bastone EB, Freer TJ, McNamara JR. Epidemiology of dental trauma: a review of the literature. Aust Dent J 2000;45:2-9.

8. acobovitz M, Ramos AM, Lima RK, Pappen FG, Fuks $A B$. Endodontic and orthodontic management of traumatically intruded teeth with horizontal root fracture: a case report. Case Rep Dent 2011;2011:250-67.

9. Yamauchi N, Yamauchi S, Nagaoka H, Duggan D, Zhong $S$, Lee SM et al. Tissue engineering strategies for immature teeth with apical periodontitis. J Endod 2011;37:390-7.

10. Gelman R, Park H. Pulp revascularization in an immature necrotic tooth: a case report. Pediatr Dent 2012;34:496-9.

11. Garcia-Godoy F, Murray PE. Recommendations for using regenerative endodontic procedures in permanent immature traumatized teeth. Dent Traumatol 2012;28:33-41.
12. Guzeler I, Uysal S, Cehreli ZC. Treatment of severe inflammatory root resorption in a young permanent incisor with mineral trioxide aggregate. J Can Dent Assoc 2011;77:b108.

13. Banchs F, Trope M. Revascularization of immature permanent teeth with apical periodontitis: new treatment protocol? J Endod 2004;30:196-200.

14. Ding RY, Cheung GS, Chen J, Yin XZ, Wang QQ, Zhang CF. Pulp revascularization of immature teeth with apical periodontitis: a clinical study. J Endod 2009;35:745-9.

15. Takushige T, Cruz EV, Asgor Moral A, Hoshino E. Endodontic treatment of primary teeth using a combination of antibacterial drugs. Int Endod J 2004;37:132-8.

16. Seale NS, Glickman GN. Contemporary perspectives on vital pulp therapy: views from the endodontists and pediatric dentists. J Endod 2008; 34:57-61.

17. Üstün $Y$, Dinçer AN, Aslan T, Sağsen B. Bir Komplike Kron-Kök Kırığının Koruyucu Restorasyonu: Vaka Raporu. Atatürk Üniv Diş Hek Fak Derg 2013;23:235-8

\section{Yazışma Adresi}

Dr. Kenan Cantekin, Erciyes Üniversitesi

Diş Hekimliği Fakültesi

Pedodonti Anabilim Dalı,

Kayseri, 38039, Türkiye

TIf: 35220766 66-29253

Faı: +90 352- 4380657

E-mail: k_cantekin@hotmail.com 